\title{
Tabagismo: a importância do diálogo entre Saúde e Direito nas ações judiciais: Evidências Científicas sobre Tabagismo para Subsídio ao Poder Judiciário
}

Smoking: the importance of dialogue between Health and Law in lawsuits: 'Scientific Evidence on Smoking Allowance for the Judiciary'

\section{Adriana Pereira de Carvalho}

Advogada, especialista em Direito do Trabalho. Coordenadora Jurídica da Aliança de Controle do Tabagismo (ACT). São Paulo, Brasil.

\section{Stella Regina Martins}

Médica, especialista em Dependência Química. Certificate on Global Tobacco Control - Johns Hopkins Bloomberg Scholl of Public Health. Membro da Comissão de Combate ao Tabagismo da Associação Médica Brasileira. São Paulo, Brasil.

A publicação Evidências Científicas sobre Tabagismo para Subsídio ao Poder Judiciário, inserida no Projeto Diretrizes, surgiu em 1999 por meio de uma parceria entre a Associação Médica Brasileira (AMB) e o Conselho Federal de Medicina (CFM) para fornecer orientações aos médicos baseada em evidências científicas (AMB, 2013). Seu principal objetivo foi produzir um material com as incontestáveis evidências sobre as doenças relacionadas ao uso e exposição aos produtos derivados do tabaco para subsidiar o Poder Judiciário em suas decisões.

De fato, trata-se de publicação que interessa a todo operador do Direito que atue em causas relacionadas ao controle do tabaco, judicial e extrajudicialmente, como magistrados, advogados e membros do Ministério Público, Defensoria Pública e Advocacia da União. E, nesse sentido, ela inova ao reunir, como autores, além de doze médicos e uma psicóloga, quatro consultores jurídicos, todos experts no controle do tabagismo.

No Brasil, assim como em outros países, todas as efetivas políticas públicas de controle do tabagismo têm sido questionadas na Justiça em ações propostas pela indústria do tabaco e seus representantes sindicais e associações de classe. A indústria também é ré em diversas ações indenizatórias por responsabilidade civil, 
propostas por vítimas do tabagismo e seus familiares, e em ações propostas pelo Ministério Público do Trabalho, referentes às condições de trabalho na fumicultura.

Dessa forma, é oportuna e necessária essa publicação, para aprimorar e ampliar o diálogo entre as áreas do Direito e da Saúde, e subsidiar o Poder Judiciário com informações atualizadas sobre tabagismo e tabagismo passivo, dependência, doenças tabaco relacionadas e doenças ocupacionais que acometem os fumicultores, já consolidadas do ponto de vista científico e fundamentadas em evidências clínicas. Além disso, a publicação traz informação sobre as estratégias adotadas pela indústria do tabaco a fim de negar tais constatações científicas e clínicas, e sobre seu papel na epidemia do tabagismo.

A proposta de realização dessa publicação teve origem na constatação de que a maioria das decisões brasileiras em ações indenizatórias não reconhece a responsabilidade civil da indústria do tabaco pelos danos causados a seus consumidores e familiares, sob fundamentos conflitantes com o consenso científico sobre tabagismo. Este fato causa indignação e questionamentos por profissionais da saúde e daqueles que atuam no controle do tabagismo, em virtude das evidências científicas que são conclusivas de que se trata de produto causador de dependência, de doenças e de morte em seus usuários e em expostos ao produto de forma passiva ou na atividade ocupacional.

A questão do livre arbítrio e o nexo de causalidade no tabagismo são searas em que a ciência da Saúde pode e deve contribuir com subsídios ao Poder Judiciário, daí a importância da publicação sob comento. É informação vital em ações judiciais sobre tabagismo, que se trata de um transtorno mental e de comportamento decorrentes do uso de substância psicoativa, conforme a Décima Revisão de Classificação Internacional de Doenças (CID-10). É a nicotina, encontrada na folha do tabaco, a referida substância psicoativa, pois leva à dependência, afetando o livre arbítrio do consumidor.

Além de contextualizar o tabagismo no Brasil e no mundo, a publicação confere detalhes sobre o processo de absorção da nicotina pelo organismo:

A partir da instalação da dependência, definida por domínio, possessão, subordinação e sujeição, a capacidade de decidir de forma livre e autônoma, ou seja, com livre arbítrio, está comprometida. O fumante é uma pessoa que contraiu uma 
doença crônica, uma dependência à nicotina, que o obriga a se expor a mais de 4.700 substâncias tóxicas, e que leva ao óbito metade de seus usuários. (...)

Após ser absorvida, a nicotina chega ao cérebro entre 7 e 19 segundos e interage com receptores presentes na periferia dos neurônios. Esses receptores liberam uma série de substâncias químicas, especialmente dopamina, que leva a uma forte sensação de prazer e euforia, fazendo com que o individuo continue fumando. Portanto, podemos afirmar que o fumante não fuma porque quer, e sim porque precisa repor a nicotina. (pág. 7)

No item síntese da evidência, a publicação é taxativa:

Assim, pode-se afirmar que há concordância por parte da comunidade científica mundial de que a nicotina é uma droga psicoativa que causa dependência aos seus consumidores. (pág. 8)

E continua a publicação:

Portanto, a partir das evidências científicas, não são mais cabíveis as expressões de que "fuma quem quer" e que os fumantes, mesmo prejudicando a si mesmos e aos outros (fumantes passivos), possam manter, em quaisquer circunstâncias, seu "livre arbítrio" preservado, pois o fumante, como dependente químico que é, não tem domínio e nem racionalidade quanto à sua dependência.

No tocante à idade de iniciação no tabagismo, a publicação evidencia se tratar de fator que afasta o livro arbítrio, já que $80 \%$ dos fumantes no Brasil iniciam o consumo antes dos 19 anos e aproximadamente $20 \%$ começaram a fumar antes dos 15 anos, e que, quanto mais precoce a idade de iniciação, maior a chance de o indivíduo tornar-se dependente da nicotina. A publicação é categórica ao afirmar que "a publicidade dos produtos do tabaco influencia a iniciação ao tabagismo" (pág. 41).

Em relação ao nexo de causalidade entre o tabagismo e doenças, a publicação analisa diversas doenças e indica as respectivas sínteses da evidência, como esta: 
Fumar é a principal causa de doenças pulmonar obstrutiva crônica (DPOC) e câncer de pulmão. A exposição à fumaça do tabaco pode induzir e agravar a asma brônquica, principalmente na infância. Fumar é um fator de risco para a tuberculose pulmonar e o principal fator de risco para a histiocitose X. (pág. 19)

Trata-se de publicação importante também para subsidiar as demais ações que envolvem o tabaco e o tabagismo, inclusive o tabagismo passivo, como as ações diretas de inconstitucionalidade que tramitam no Supremo Tribunal Federal e na Justiça Federal, em que se questionam as políticas públicas de controle do tabaco.

Nesse sentido, a publicação evidencia a importância das chamadas "leis antifumo", nas quais se proíbe o fumo em locais fechados, destacando que o tabagismo passivo é também uma questão ocupacional:

As principais doenças ou manifestações clínicas relacionadas com o tabagismo passivo ocorrem em adultos expostos no ambiente domiciliar ou de trabalho. O fumo passivo está relacionado com diversas doenças respiratórias e sistêmicas. (pág. 44)

Na publicação, ainda, há referência à indústria do tabaco e seu papel na epidemia do tabagismo, com destaque para estes trechos:

Milhões de documentos internos das principais corporações transnacionais de tabaco, abertos ao público nos Estados Unidos e no Reino Unido devido a processos judiciais, expuseram as mais diversas manobras e estratégias para promover a iniciação de crianças e adolescentes no tabagismo, manipular informações relevantes para a saúde pública e, sobretudo, para influenciar governantes, políticos e reguladores e impedir a adoção de medidas eficientes para redução do consumo de produtos de tabaco. (...)

Por tudo isso, em seu relatório sobre a epidemia e tabagismo no mundo, publicado em 2008, a Organização Mundial de Saúde reconhece a indústria do tabaco como "vetor que dissemina doença e morte". (págs. 46 e 49) 
Quando se trata de tabagismo, imprescindível a menção à Convenção Quadro para o Controle do Tabaco (págs. 50 e segs.), tratado internacional de saúde pública, ratificada pelo Brasil por meio do Decreto № 5.658, de 2006, que visa impedir o avanço do tabagismo no mundo, por meio de medidas como proteção contra o fumo passivo, uso de advertências nas embalagens de cigarros, proibição da publicidade, promoção e patrocínio etc.

Evidências Científicas sobre Tabagismo para Subsídio ao Poder Judiciário consiste em importante fonte de informação para operadores do Direito, notadamente magistrados, para que se evitem premissas equivocadas no julgamento de ações sobre o tabaco e/ou tabagismo, como no caso da afirmação de que há livre arbítrio no ato de fumar.

Espera-se com essa publicação o início de um amplo e profícuo diálogo entre os profissionais que atuam nas áreas do Direito e da Saúde no que tange ao compartilhamento de saberes.

\section{Para acesso gratuito à publicação:}

ASSOCIAÇÃO MÉDICA BRASILEIRA (AMB). MINISTÉRIO DA SAÚDE / INSTITUTO NACIONAL DE CÂNCER JOSÉ ALENCAR GOMES DA SILVA, ALIANÇA DE CONTROLE DO TABAGISMO (ed.). Evidências Científicas sobre Tabagismo para Subsídio ao Poder Judiciário, 2013. Rio de Janeiro: Associação Médica Brasileira. Ministério da Saúde / Instituto Nacional de Câncer José Alencar Gomes da Silva, Aliança de Controle do Tabagismo, 2013.

Disponível em: http://www.projetodiretrizes.org.br/diretrizes12/tabagismojudiciario.pdf 